\title{
www.czasopisma.pan.pl \\ Tribological Response of Heat Treated AISI 52100 Steels Against Steel and Ceramic Counterparts
}

\author{
E. Türedi *, M. Yilmaz, V. Senol \\ Kocaeli University, Faculty of Engineering, Dept. of Metallurgical and Materials Eng., \\ 41380 Kocaeli, Turkey \\ *Corresponding author. E-mail address: enbiya.turedi@kocaeli.edu.tr)
}

Received 10.04.2017; accepted in revised form 10.07.2017

\begin{abstract}
AISI 52100 bearing steels are commonly used in applications requiring high hardness and abrasion resistance. The bearing steels are working under dynamic loads in service conditions and their toughness properties become important. In order to provide the desired mechanical properties, various heat treatments (austenizing, quenching and tempering) are usually applied. In this study, AISI 52100 bearing steel samples were austenized at $900^{\circ} \mathrm{C}$ for $1 / 2 \mathrm{~h}$ and water quenched to room temperature. Then tempering was carried out at $795^{\circ} \mathrm{C}, 400^{\circ} \mathrm{C}$ and $200^{\circ} \mathrm{C}$ for $1 / 2 \mathrm{~h}$. In order to investigate the effect of heat treatment conditions on wear behavior, dry friction tests were performed according to ASTM G99-05 Standard with a 'ball-on-disk' type tribometer. The samples were tested against steel and ceramic counterparts using the parameters of $100 \mathrm{~m}$ distance and $30 \mathrm{~N}$ load and $0.063 \mathrm{~m} / \mathrm{s}$ rotational speed. After wear test, the surface characterization was carried out using microscopy. Wear loss values were calculated using a novel optical method on both flat and counterpart specimens.
\end{abstract}

Keywords: Wear resistant alloys, Bearing steel, Tribology, Microscopy, Characterization

\section{Introduction}

Today, the bearing steels are used as one of the key components in design and manufacturing of various machinery parts. They must, therefore, ensure a series of requirements including wear and fatigue resistance under rolling/sliding contacts, axial loadings and crack propagation and growth, as well as high or adequate hardness, strength, toughness, ductility and last but not least, corrosion resistance [1-5].

Alloy compositions including carbon amount between $0.8-1.1$ wt- $\%$ and substitutional solute elements amount up to $3.0 \mathrm{wt}-\%$ are commonly chosen for bearing applications. The matrices of these groups of steel alloys are preferably transformed to martensite after quenching in suitable media, e.g. oil or salt. Due to the relatively high alloy elements and carbon content, martensitic matrices need to be tempered to suppress the excess brittleness. Hardenability depth is another important key factor, particularly for those steel parts, which possess relatively large cross-sectional area. When this depth value is not sufficient at given dimensions of bearing steel part, the case hardening treatment or increasing alloy content can be introduced $[1,3]$.

The spheroidization treatment plays a critical role in the manufacturing process of this sort of hypereutectoid steels. Because proeutectoid cementite can easily be formed at prior austenite grain boundaries on cooling, and hence resulting an inappropriate microstructure in terms of rolling contact resistance. The spheroidization treatment before machining and hardening 
can eliminate that unfavorable carbide network morphology in microstructure and so enhance rolling wear resistance $[1,3,6$ 7].Previous studies [8-9] showed that the bearing steels with bainitic matrices or tempered at relatively higher temperatures martensitic microstructures yield advantageous wear resistant parts for the applications that mentioned above. There was a lack of harder counterpart condition in dry sliding contact pairs in those studies. In this study, bearing steels heat treated in various conditions were tribologically tested in dry sliding against alumina and $100 \mathrm{Cr} 6$ counterpart.

The main purpose of this study was to evaluate heat treated bearing steels in wear test against harder ceramic counterparts to see if there are any difference between them in terms of wear resistance under the tribological loading, which is mainly driven by abrasive wear mechanism rather than adhesive one that compared in previous studies [8-9]. A recently published novel method [11-12] enables to obtain profilometric measurements on wear track with precise volumetric wear loss values calculating from the math formulae based on the track profile geometry formed during the wear test.

\section{Experimental}

\subsection{Heat treatment and surface preparation}

The working material in the experimental study, Fe-0.95C$0.21 \mathrm{Si}-0.36 \mathrm{Mn}-1.44 \mathrm{Cr}$ is a well-known AISI 52100 grade alloy and commonly used as bearing steel in wide variety applications. The delivered specimens from a local supplier cut up into slices had dimensions of $12-15 \mathrm{~mm}$ in height and $40 \mathrm{~mm}$.

The austenization treatment at $900^{\circ} \mathrm{C}$ for $1 / 2 \mathrm{~h}$ was applied to all specimens, followed by water quenching to room temperature (RT) without cracking in their structures, whose dimensions could compensate this sort of supercooling. The specimens were split into three groups in which they were heat treated with various parameters as listed in Table 1 . The specimens were then polished and etched for microscopic investigation. Nital (vol.\%-3) was used as the etchant. Their hardness values were measured on metallographically prepared surfaces using Vickers method under a load of $10 \mathrm{~kg}-\mathrm{f}$.

The group of G1 specimens was heat treated to obtain a spheroidized cementite structure very finely distributed in the ferritic matrix instead of regular pearlitic formation (see Fig. 1). For this purpose, they were tempered or let's say austenized at $795^{\circ} \mathrm{C}$ for $1 / 2 \mathrm{~h}$ and then furnace temperature set to $680^{\circ} \mathrm{C}$ with a cooling rate of $370 \mathrm{~K} / \mathrm{h}$. The second leg of cooling was continued in the furnace with the self-cooling condition to RT. This group has the lowest hardness and is however used as reference materials for the calculation of math equations.
The group of $\mathrm{G} 2$ specimens was tempered at $400^{\circ} \mathrm{C}$ and their microstructures consist of typical tempered martensite structure (Fig. 2). The backscattered electron imaging with compositional mode (BEI/C) in Fig. 2 reveals the randomly oriented patches of tempered martensite structure with a distributed carbide grains in dark contrast.

The group of G3 specimen showed slightly tempered and stress relieved martensitic matrix with some additions of retained austenite in its microstructural investigation, due to relatively lower tempering temperature $\left(200^{\circ} \mathrm{C}\right)$, as seen in $\mathrm{BEI} / \mathrm{C}$ mode scanning electron microscope (SEM) image (see Fig. 3).

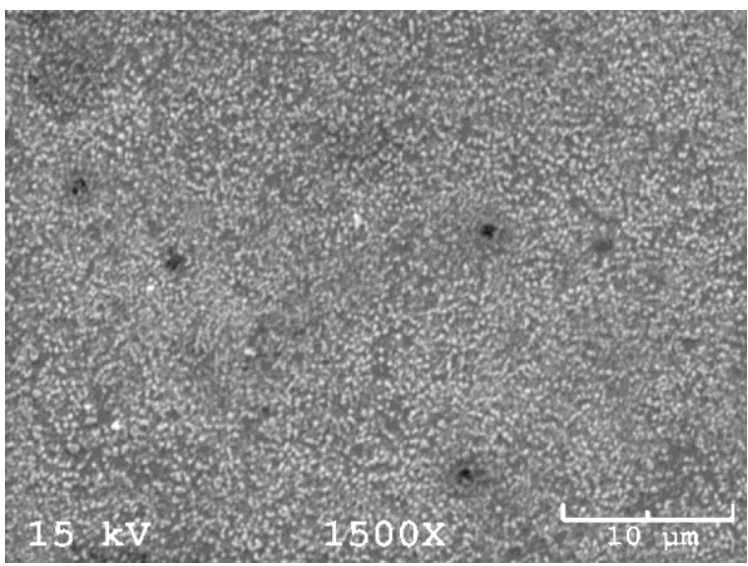

Fig. 1. Etched microstructure of G1 specimen in SEM (with secondary electron imaging, (SEI) mode) shows very fine spherical cementite grains distributed in a ferritic matrix [9]

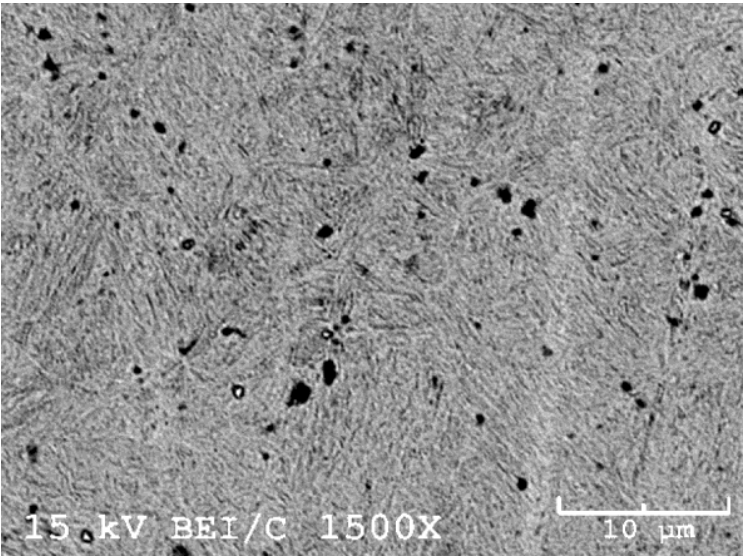

Fig. 2. Etched microstructure of G2 specimen in SEM (BEI/C mode) consists of tempered martensite with randomly distributed carbide grains revealed in dark contrast

Table 1.

Specimen groups and their heat treatment conditions applied

\begin{tabular}{|c|c|c|c|c|c|}
\hline Groups & Austenization & Quenching & Tempering & Remarks & Hardness, HV-10 \\
\hline G1 & \multirow{3}{*}{$1 / 2 \mathrm{~h} @ 900^{\circ} \mathrm{C}$} & \multirow{3}{*}{ in water } & $1 / 2 \mathrm{~h} @ 795^{\circ} \mathrm{C}$ & Slow cooling to $680^{\circ} \mathrm{C}$ then to RT in furnace & $222.7 \pm 2.47$ \\
\hline G2 & & & $1 / 2 \mathrm{~h} @ 400^{\circ} \mathrm{C}$ & \multirow{2}{*}{ Air cooling to RT } & $587.1 \pm 8.27$ \\
\hline G3 & & & $1 / 2 \mathrm{~h} @ 200^{\circ} \mathrm{C}$ & & $765.3 \pm 18.9$ \\
\hline
\end{tabular}


Table 2.

Tribological test parameters used against heat treated bearing steels in dry sliding test

\begin{tabular}{lllllll}
\hline \multirow{2}{*}{ Load $(\mathrm{N})$} & \multicolumn{2}{c}{ Counterpart } & \multicolumn{2}{c}{ Sliding } & speed \\
\cline { 2 - 6 } & material & diameter $(\mathrm{mm})$ & hardness $(\mathrm{HV}-10)$ & distance $(\mathrm{m})$ & Temperature & Humidity \\
\hline \multirow{2}{*}{30.0} & $100 \mathrm{Cr} 6$ & 5.00 & 843.8 & 0.063 & 100.0 & RT \\
\cline { 2 - 6 } & $\mathrm{Al}_{2} \mathrm{O}_{3}$ & 6.00 & 1353.7 & N/A \\
\hline
\end{tabular}

\subsection{Wear test and characterization}

For wear characterization, "ball-on-disk" type sliding test in dry condition according to ASTM G99-05 Standard [10] were carried out using a tribometer from Nanovea. Apart from previous studies [8-9], two variants as counterpart were used against flat AISI 52100 bearing steel specimens. These counterparts are pure alumina and DIN 100Cr6 (equivalent to AISI 52100) steel balls. Related details for the dry sliding test are listed in Table 2. The flat specimens were tested in dry sliding condition afterward metallographic preparation procedures and cleaned with acetone. After the tribological test, the worn surfaces of both flat bearing steel specimens and the ball-shaped counterparts were examined in the optical microscope and their worn volumes were calculated using novel optical profilometric techniques as described in previous studies [11-12].

\section{Results and Discussion}

The change in coefficient of friction (COF) values with sliding distance during tests were presented in Fig. 4. Sliding pairs of various bearing steel specimens against $100 \mathrm{Cr} 6$ counterpart balls (Fig. 4a) yielded slightly different friction levels in first half of the total sliding distance, but almost same at the second part of it. Their kinematic COF values were about 0.25 in steady state condition. Their frictional behavior against alumina ceramic counterpart balls resembles previous ones but the average COF values yielded around 0.20 in steady state condition. In both cases, G2 specimens yielded lower COF values than that of others, particularly at the first half of the test distance.

As stated before, the sliding surfaces were cleaned at the beginning. That means the counterpart ball slides on a very smooth flat specimen surface at the initial period of wear test. However, the maximum Hertzian contact pressure values for test pairs under given tribological test conditions, point out that the dry sliding test starts with a plastic deformation on flat specimen surfaces. For example, G1, G2 or G3 specimens against 100Cr6, suffer from a maximum Hertzian contact pressure level of 2238.5 $\mathrm{MPa}$, while having a shear stress level of $694 \mathrm{MPa}$ under $38 \mu \mathrm{m}$ depth of their original surfaces, according to the calculated results. On the other hand, same specimens against alumina counterpart balls are exposed to a maximum Hertzian contact pressure level of $2341.7 \mathrm{MPa}$, while having a shear stress level of $726 \mathrm{MPa}$ under $38 \mu \mathrm{m}$ depth of their original surface.

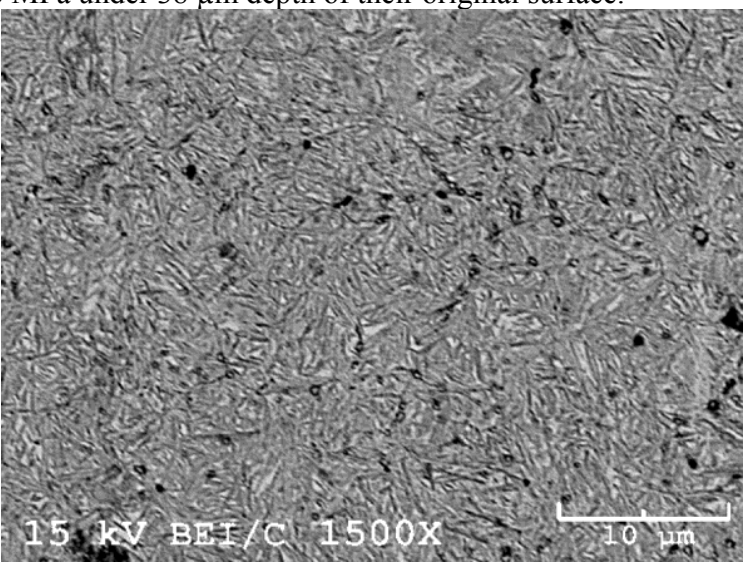

Fig. 3. Etched microstructure of G3 specimen in SEM (BEI/C mode) shows mainly martensitic structure with some retained austenite revealed in light gray contrast between wedge type martensite plates

There is obviously elastoplastic contact between test pairs in all conditions. Briefly, the hard and spherical counterpart (the ball) indents the relatively soft and flat specimen surface at the beginning and then it is forced to slide. It turns into predominantly abrasive wear [14] under these circumstances. Since the G1 specimen has relatively lower hardness and hence a better deformation capability, the micro-ploughing (Fig. 5) plays a critical role in this case both against hard steel and ceramic counterpart balls. G1 specimens should, therefore, have relatively deeper indentation effect on its surface; that leads to higher friction and COF values, at least during running-in period. Its COF value against $100 \mathrm{Cr} 6$ counterpart yielded relatively higher than that of against ceramic one. Another wear mechanism, adhesion may play a critical role here. Metal-metal pairs should have much more tendency to cold welding at given conditions, than that of metal-ceramic pairs. Likewise, cold welding possibility in the latter case must be minimum due to their different material properties including bond structure, chemical stability etc. After a running-in period, micro-cutting and work hardening effect should be effective in G1 specimen-counterpart pairs. That yields a slight decrease in COF values as seen in Fig. $4 \mathrm{a}$ and $\mathrm{b}$. 
Table 3.

Tribological test results after wear characterization

\begin{tabular}{ccccccc}
\hline \multirow{2}{*}{ Groups } & \multicolumn{2}{c}{ Sliding pairs: AISI 52100 vs. 100Cr6 balls } & \multicolumn{2}{c}{ Sliding pairs: AISI 52100 vs. Alumina balls } \\
\cline { 2 - 4 } & $\begin{array}{c}\text { Coefficient of } \\
\text { friction }(\mu),-\end{array}$ & \multicolumn{2}{c}{ Volume loss $\left(\mathrm{mm}^{3}\right)$} & & $\begin{array}{c}\text { Coefficient of } \\
\text { friction }(\mu),-\end{array}$ & \multicolumn{2}{c}{ Volume loss $\left(\mathrm{mm}^{3}\right)$} \\
\cline { 3 - 4 } & 0.26 & 1.243 & 0.019 & 0.22 & 1.942 & in ball \\
\hline G1 & 0.23 & 0.047 & 0.018 & 0.18 & 0.055 \\
\hline G3 & 0.23 & 0.011 & 0.029 & 0.20 & 0.031 \\
\hline
\end{tabular}

Meanwhile, the debris formed at the interface should be partly oxidized and smeared throughout the wear track on the flat specimen surface. That means a third wear mechanism, the tribocorrosion [14] should also be effective as of steady-state period.
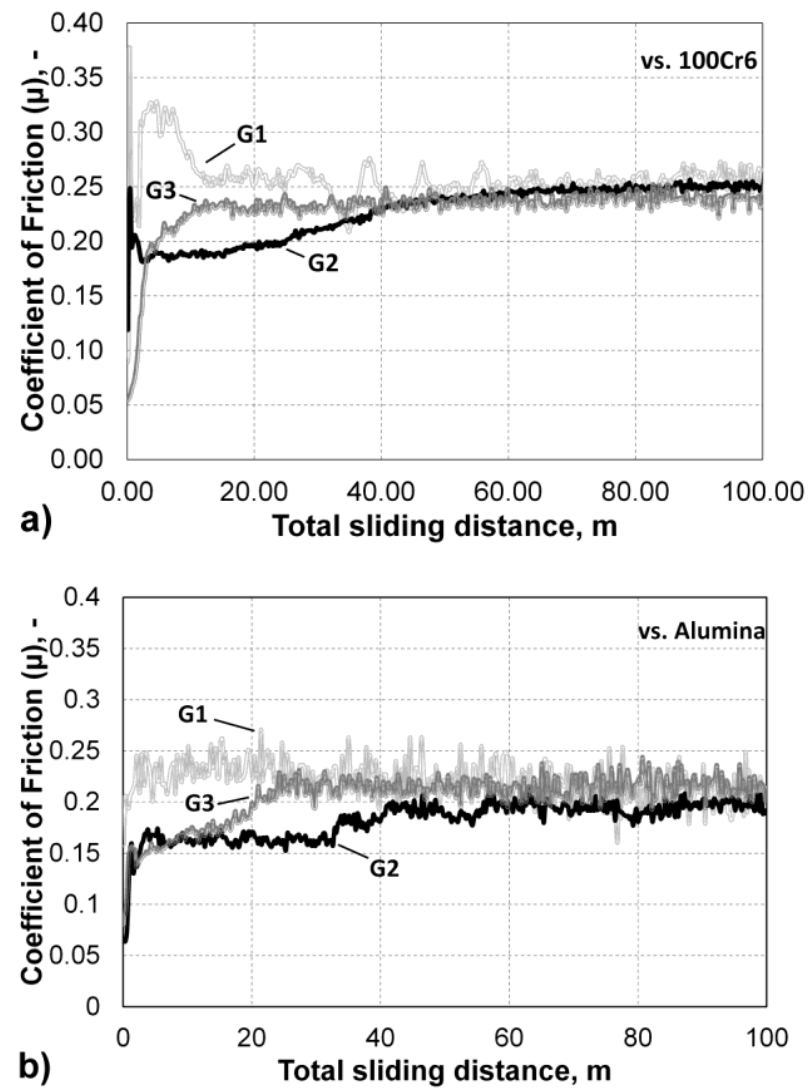

Fig. 4. Coefficient of friction - total sliding distance diagrams, bearing steel flat specimens against $100 \mathrm{Cr} 6$ (a), and against alumina balls (b)

Due to its moderate hardness and microstructure of tempered martensite, G2 specimens do not plastically deform as much as G1 specimens at the running-in period. When the inherent oxide film on both sliding pairs was broken and cleaned, the two/three body abrasion should be effective as predominant wear mechanism. Micro-cutting and work hardening effects play an important role in this period. The spalling of partly oxidized debris parts, as well as work hardened and partly micro-cracked regions from flat specimen surface, are responsible for the wear losses in the steady-state period.
The G3 specimen was relatively hardest among others. Therefore, they should be more brittle and less plastically deformable than others should. This may lead to a wear mechanism with the mixture of micro-cutting and micro-cracking, more or less in the running-in period. When it is covered with partly oxidized debris, the surface should have a protective layer and hence not increase anymore through the steady-state period.

The counterpart materials effect on tribological response can be outlined that they did not change the tribological conditions fundamentally, but probably amended the weight ratio between mixed mechanisms, e.g. adhesive wear in the pairs of metalceramic counterparts should be less effective than that of metalmetal ones, thus leading to a decrease in COF values in dry sliding tests.

The tribological test results calculated from direct microscopic measurements were listed in Table 3. COF values were calculated as average values from sliding test result tables. Volume loss values were determined from cross-sectional profiles for each specimen. The selected wear track profiles measured using optical microscope is given in Fig. 5. The width level of wear tracks belongs to metal-ceramic pairs seem to be wider than that of metal-metal pairs. It must be noted that ceramic counterpart balls have a bigger diameter (see Table 2). Equally spaced six cross-sectional profiles for every wear track were measured and used for calculation of worn volume loss values as required by the ASTM standard G99-05 [10]. Although there were important amount of wear on flat specimens, which are not presumed in related math formulae described by ASTM G99-05 Standard, the worn volume in counterpart balls were still calculated by these formulae, since it has been shown in a previous study [12] that the calculation error in this condition is less than $5 \%$, generally. It must be noted that "the piling-up" formation (or so-called micro-ploughing effect) on both sides of worn track profile could also be easily defined if there any. This piling-up formation [13-14] implies that there is plastic deformation during indentation of the counterpart ball tip into to flat specimen surface.

The most wear resistance was obtained in G3 specimens as expected and as found in a previous study [9], in which the volume loss values were determined using a different method. G2 specimens yielded lower wear resistance than G3 against both counterpart types, but the difference between them is quite small and additionally wear loss in counterpart is much more advantageous in G2 specimens vs. steel/ceramic ball pairs, than those with G3 specimens, in all circumstances. Likewise, the COF values are also relatively lower in G2 specimens particularly at first half of the sliding tests (see Fig. 4). It implies that dry sliding between G2 and counterpart pairs brings much more advantageous lower friction during first $40-50 \mathrm{~m}$ of total distance, but eventually the worn debris formed covers throughout the 
interface and the COF reaches the same level of 0.20 or 0.25 , depending on counterpart type.

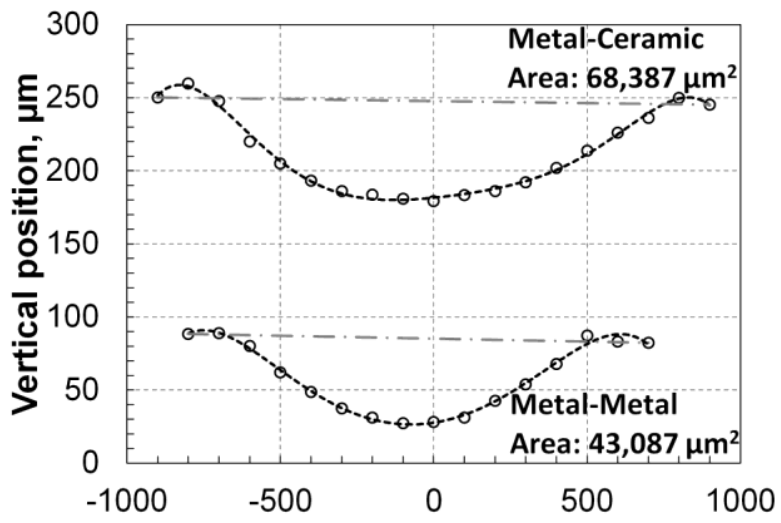

a) Horizontal position, $\mu \mathrm{m}$

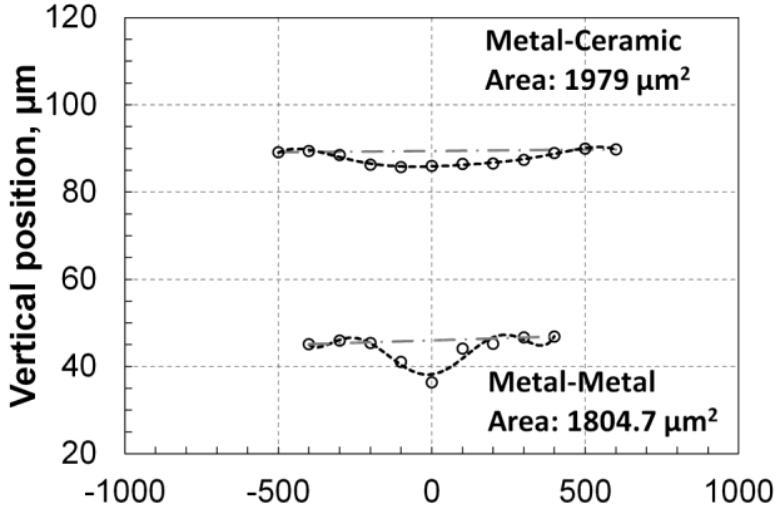

b)

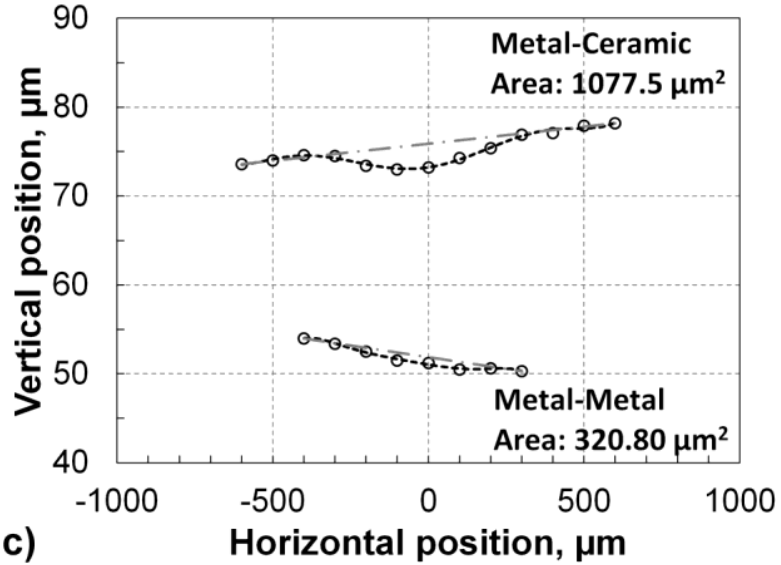

Fig. 5. The selected profiles measured from cross-sectional worn surface of flat specimens after sliding test; G1 specimens (a), G2 (b) and G3 (c)

The worn track investigations show that the wear mechanisms were a mixture of abrasive and adhesive in given sliding pairs. In Fig. 6a, the worn surfaces of the G2 specimen and its $100 \mathrm{Cr} 6$ counterpart are shown. Abrasive tracks and smeared debris layers are evident. Worn tip of the counterpart has a regular and circular shaped contour. Fig. $6 \mathrm{~b}$ shows the worn track surface of the flat G2 specimen and its alumina ball worn tip at left-hand corner. The width value is wider than that of the G2-100Cr6 pair, but adhesive and abrasive wear marks are clear.
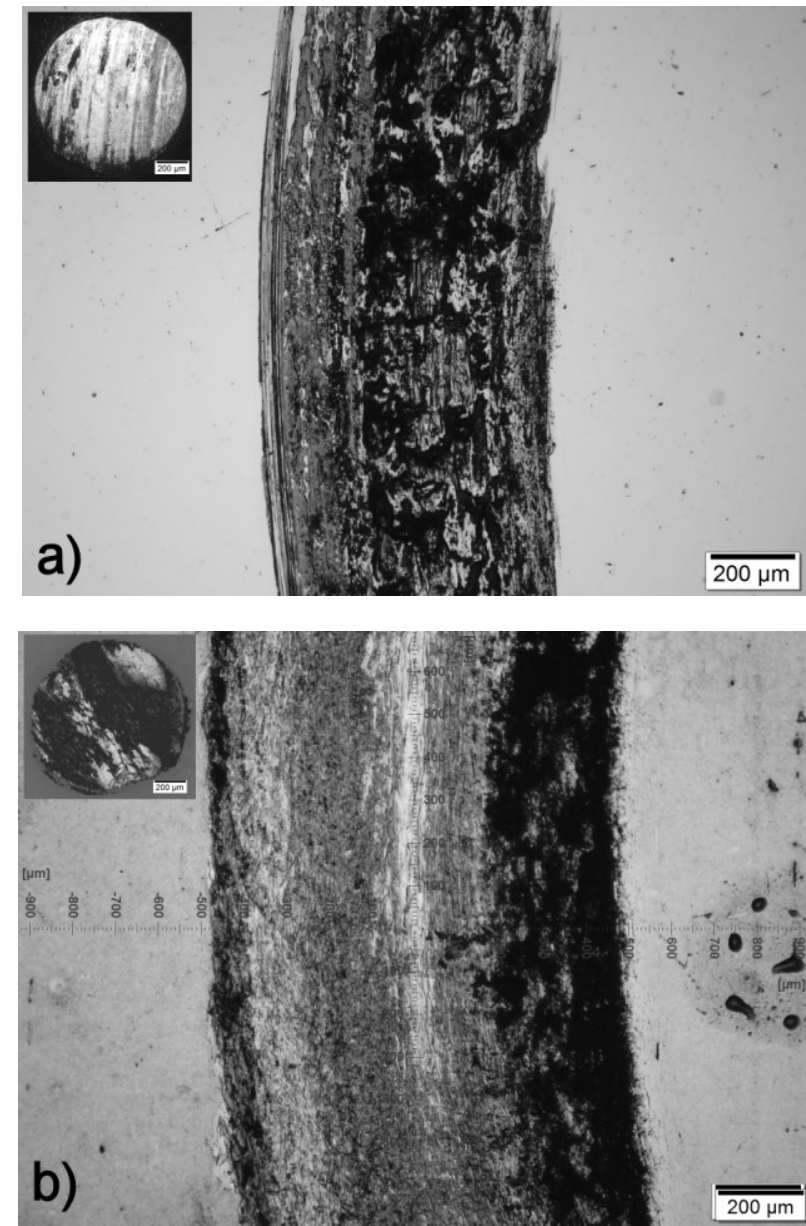

Fig. 6. Worn surfaces of G2 specimen against its $100 \mathrm{Cr} 6$ (a) or its alumina counterpart (b) shown at upper left corner

The worn surface examinations in G3 specimens gave same wear characteristics with G2 specimens in terms of wear mechanisms, which are a mixture of adhesive and abrasive ones. It is possible to see, for example, abrasive wear tracks in Fig. 7a, as well as some debris (dark regions), smeared at the interface. The wear track width of G3 specimen worn against ceramic counterpart is wider than that of specimen worn against $100 \mathrm{Cr} 6$ ball (Fig. 7b).

If the wear volume amounts of counterparts in Table 3 are considered, G2 specimens look like better and more advantageous than that of other group specimens since their volume loss amounts are either lower or almost equal to that of G1 specimens, which are not wear- resistant specimens. In other words, the sliding pairs including G2 specimens yielded minimum wear loss in total including flat and counterpart specimens than that of particularly G3 specimens and their sliding pairs. This situation can also be observed in COF-total sliding distance diagrams 
presented in Fig. 4, especially at first half of the test distance, G2counterpart pairs yielded relatively lower friction than others in both cases did.
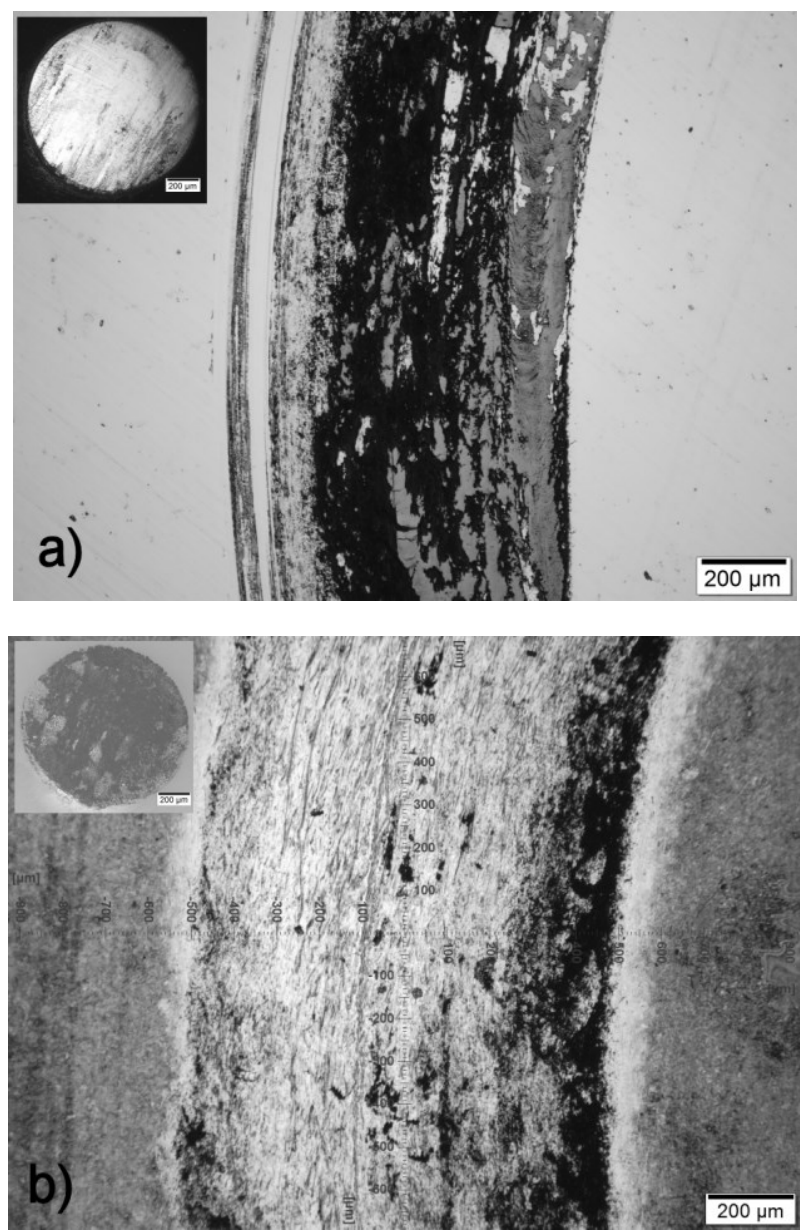

Fig. 7. Worn surfaces of G3 specimen against its $100 \mathrm{Cr} 6$ (a) or its alumina counterpart (b) shown at upper left corner

Bhadeshia [1] reported a study from Paland [15] in which a diagram was presented. This diagram showed the change of fretting-corrosion induced weight loss with the hardness of materials tested, in given test conditions. In the scope of the present work, volume loss data were examined in terms of the effect of specimen hardness at different tribological conditions. The resulting diagram concerning the interrelation mentioned above was exhibited in Fig. 8. This relation was evaluated in two separate data series in which two different counterparts used against bearing steel specimens. Therefore, two different data series and their trendline functions calculated by MS Excel were placed. Using logarithmic axes on both sides and exponential functions, a linear interrelation between volume loss and materials' hardness with high determination coefficients $\left(\mathrm{R}^{2}\right.$ values) were obtained.

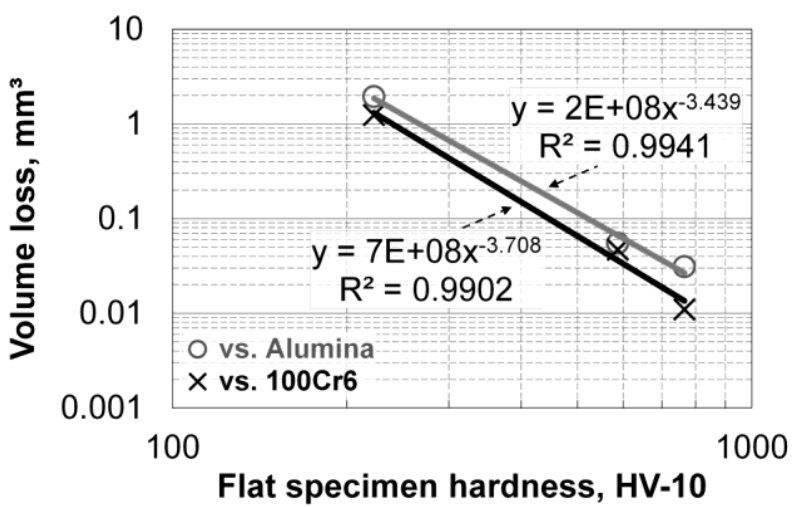

Fig. 8. Volume loss in flat specimens varies with their hardness level in given tribological conditions

\section{Conclusions}

AISI 52100 is a well-known bearing steel and used frequently wear resistant alloy needed applications, where hardness, wear resistance, fatigue resistance, last but not least toughness are demanded. Spheroidization treatment is a key step in manufacturing this group of alloys before hardening and tempering in order to eliminate secondary carbide network at prior austenite grain boundaries and hence to increase wear resistance. Hardening through a martensitic matrix in microstructure is one of the methods to obtain a wear resistant steel structure but its lack of toughness is a major shortcoming in these group of steel alloys. There are plenty of studies indicating the advantageous use of bainitic or tempered martensitic structures in wear resistant applications [1,8-9].

In this study, metal-metal and metal-ceramic interactions in dry sliding pairs were examined and their interrelations and equations determined with high determination coefficients. According to results obtained, the following conclusions were outlined:

- Wear mechanisms were characterized as a mixture of abrasive, adhesive and tribo-corrosion types on all worn surfaces. However, abrasive wear is predominant one among them. Micro-ploughing and micro-cutting induced track formation in friction directions are evident for abrasive wear, while smeared and then partly spalled debris layers for adhesive and tribo-corrosion wear.

- The change in counterpart material from steel to ceramic did not affect wear phenomenon on flat specimen surfaces fundamentally. According to results, there were differences in the amount of volume loss, contact area, the ratio of adhesive wear mechanism in total wear behavior, etc. But the predominant mechanism was abrasion in both counterpart types.

- G3 specimens yielded best wear resistance in given tribological conditions, but their counterparts worn at most in comparison with other counterparts.

- G2 specimens showed quite close performance in wear resistance to G3 specimens, moreover, their counterparts showed equal or lesser to that of G1 specimens, which had a quite soft structure for machining purposes. 
- When the wear volume loss values in counterparts are considered, G2 specimens yielded better and more advantageous results than others in terms of volume loss amounts of both flat specimens and ball shaped counterparts, in which the COF values are lowest among others at first half part of the dry sliding tests.

- The bearing steel specimens heat-treated in various conditions were divided groups and tested against ceramic and steel counterparts. The volume loss in flat specimens was mathematically defined with a function of their hardness under given tribological conditions. The resulting equations represent the interrelations with high determination coefficients and successfully.

\section{References}

[1] Bhadeshia, H.K.D.H. (2012). Steels for bearings. Progress in Materials Science. 57(2), 268-435. DOI: 10.1016/ j.pmatsci.2011.06.002.

[2] Wang, Y., Lei, T.C. \& Gao, C.Q. (1990). Influence of isothermal hardening on the sliding wear behaviour of 52100 bearing steel. Tribology International. 23, 47-53. DOI: 10.1016/0301-679X(90)90072-W.

[3] Bhadeshia, H.K.D.H. (2010). Mechanical bearings. Cambridge: University of Cambridge, Technical report.

[4] Zaretsky, E.V. (2012). Rolling Bearing Steels-A Technical and Historical Perspective. Cleveland $\mathrm{OH}$ : NASA Glenn Research Center, Technical Report, NASA/TM 2012217445.

[5] Polonsky, I.A. \& Keer, L.M. (1995). On white etching band formation in rolling bearings. Journal of the Mechanics and Physics of Solids. 43, 637-669. DOI: 10.1016/00225096(95)00001-Y.

[6] Chattopadhyay, S. \& Sellars, C.M. (1982). Kinetics of pearlite spheroidisation during static annealing and during hot deformation. Acta Metallurgica. 30(1), 157-70. DOI: 10.1016/0001-6160(82)90055-4.

[7] Verhoeven, J.D. (2005). Metallurgy of Steel for Bladesmiths \& Others who Heat Treat and Forge Steel. Iowa State University. Retrieved from archive.org https://tinyurl.com/glz264k.

[8] Polat, S., Türedi, E., Atapek, S.H. \& Köseoglu, M. (2013). Wear Behaviour of Heat Treated 100Cr6 Steels. Materials Testing. 55(4), 290-293. DOI: 10.3139/120.110437.

[9] Türedi, E. (2015). The Effect of Heat Treatment on Tribological Behavior of AISI 52100 Steels under Dry Sliding Condition. In $4^{\text {th }}$ International Conference of Engineering Against Failure (ICEAF IV), 24-26 June 2015 (pp. 98-104). Skiathos, Greece: LTSM (University of Patras).

[10] ASTM G99-05 (2010). Standard Test Method for Wear Testing with a Pin-on-Disk Apparatus, ASTM International, West Conshohocken, PA, www.astm.org.

[11] Türedi, E. (2016). A novel approach in determining wear volume: precise optical profilometric measurement with limited depth of field in light microscopy. In 1st International Mediterranean Science and Engineering Congress (IMSEC 2016), 26-28 October 2016 (pp. 2602-2610). Adana-Turkey: Cukurova University. (in Turkish).

[12] Türedi, E. (2016). Direct Profilometric Measurement of Wear Volumes using Optical Microscope in Cast Iron Alloys After Dry Sliding Test. In 1st International Mediterranean Science and Engineering Congress (IMSEC 2016), 26-28 October 2016 (pp. 4472-4480). Adana-Turkey: Cukurova University. (in Turkish).

[13] Tabor, D. (1951). The Hardness of Metals. Oxford: Clarendon Press.

[14] Zum Gahr, K.H. (1987). Microstructure and Wear of Materials. Amsterdam: Elsevier Science Publ. B.V.

[15] Paland, E.G. (1982). Fretting corrosion in rolling bearings cause and avoidance. Sutton Coldfield (UK): INA Bearing Comp. Ltd. Technical Report. 